\title{
Chemical components and emulsification properties of mucilage from Dioscorea opposita Thunb
}

\section{Ma, Fanyi}

2017-08-01

Ma , F , Zhang , Y, Yao , Y, Wen , Y, Hu , W , Zhang , J , Liu , X, Bell , A E \&

Tikkanen-Kaukanen, C 2017 , ' Chemical components and emulsification properties of

mucilage from Dioscorea opposita Thunb ' , Food Chemistry , vol. 228 , pp. 315-322 . https://doi.org/10.1016/j.foodc

http://hdl.handle.net/10138/308380

https://doi.org/10.1016/j.foodchem.2017.01.151

cc_by_nc_nd

acceptedVersion

Downloaded from Helda, University of Helsinki institutional repository.

This is an electronic reprint of the original article.

This reprint may differ from the original in pagination and typographic detail.

Please cite the original version. 


\section{Chemical components and emulsification properties of}

mucilage from Dioscorea opposita Thunb.

3 Running Title: Characteristics and Emulsifications of Chinese yam mucilage

5 Fanyi MAª, Yun ZHANG ${ }^{a}$, Yanna YAO $^{\mathrm{a}}$, Yurong $\mathrm{WEN}^{\mathrm{a}}$, Weiping HU', Mingjing LI,

$6 \quad$ Xiuhua Liu $^{\text {a*}}$, Alan Bell ${ }^{\mathrm{b}}$, Carina Tikkanen-Kaukanen ${ }^{\mathrm{c}}$

b. Department of Food and Nutritional Science, University of Reading, Whitenights,

12 Reading, RG6 6AP, UK

13 c. Ruralia Institute, University of Helsinki, Lönnrotinkatu 7, 50100 Mikkeli, Finland

*Corresponding Author

19 Prof. Xiuhua LIU,

20 Key Lab. of Natural Medicine and Immune-Engineering of Henan Province,

21 College of Chemistry and Chemical Engineering,

22 Henan University, Kaifeng, 475004, China.

23 Email: liuxiuhua@henu.edu.cn

24 Telephone: +86-371-22199505. 


\section{Abstract}

The properties of mucilage obtained from Dioscorea opposita, generated during

27 industrial manufacturing were investigated in this study. Characteristics such as

28 monosaccharide content, amino acid content, molecular weight, and structural features

29 were measured, whereas morphology was observed using a scanning/transmission

30 electron microscope. Additionally, emulsification properties at different concentrations

$31(0.2 \%, 0.4 \%, 0.6 \%, 0.8 \%$, and $1.0 \%)$ and under acidic and basic $\mathrm{pH}(5.0$ and 9.0)

32 conditions were studied. The results showed that emulsions prepared from mucilage

33 and medium-chain triglycerides presented more effective emulsifying functions and

34 higher stability, especially at low concentrations. Both, acidic and basic conditions

35 improved the overall emulsification properties, which suggested that the isoelectric

36 point of amino acids may be involved in the emulsification properties. The results of

37 this study show that mucilage from Dioscorea opposita can be considered as a

38 sustainable resource of a natural emulsifier obtained from industrial waste.

39

40 Key Words: Chinese yam, Dioscorea opposita Thunb., mucilage, emulsification 41 properties 


\section{Introduction}

The yam (Family Dioscoreaceae) is an important tropical root used as a functional food as well as a source for natural medicine due to several pharmacological activities (Huang et al., 2011). Dioscorea opposita Thunb. is a kind of Chinese yams (CY) that is rich in starch, water-soluble polysaccharides, and mucilage (Herlina, 2015). Mucilage defined as a polysaccharide with unique viscosity characteristics is widely used in the pharmaceutical and food industries as a thickening agent and emulsion stabiliser (Lee et al., 2003). According to Kilho et al. (1985) and Ohtani \& Murakami (1991), the water-soluble mucilage from Dioscorea batatas Dence is rich in glucomannan. Myoda et al. (2006) studied the interaction between mannan and soluble proteins in Dioscorea opposita mucilage (DOM), which affects the viscosity of DOM.

Several pharmacological effects of Chinese yam mucilage (CYM) have been reported, including antioxidant, enzyme inhibitory, and antimutagenic activities (Lee et al., 2003; Hsu, et al., 2003; Zhang et al., 2016).

Emulsifying agents consist of a water-soluble polar component (hydrophilic) and a non-polar, water-insoluble component (hydrophobic).These agents are important in the food industry as they improve the sensory quality, flavour, texture, palatability, mouthfeel, and general appearance of the final products (Dickinson \& Stainsby, 1988). Previous studies have reported that mucilage from various plants such as yellow mustard and chia (Salvia hispanica L.) have emulsification and/or stabilisation properties (Wu et al., 2015; Capitani et al., 2016). Therefore, in this study we investigated the emulsification properties of DOM which is a potential candidate for 
food emulsifier.

Usually harvested in November, Dioscorea opposita is a seasonal crop with a short shelf-life, as it contains protein and steroidal saponins, which reduce the quality of the yam during storage (Yang \& Lin, 2008; Xue et al., 2015). Therefore, dried slices of Dioscorea opposita are prepared on an industrial scale. However, DOM generated during industrial processing is discarded ( $\mathrm{Li}$ et al., 2016). DOM is a high-yielding, natural product that is easily extracted and used as an additive in food applications and functional food products. Medium-chain triglyceride (MCT) is used as a fat/lipid carrier in food flavours, essences, and pigments, which are widely used in the food industry (Télessy et al., 2009). Hence, in this study, the oil/water (O/W) emulsion was made by emulsification using MCT.

Gum arabic (GA), one of the most extensively used exudate gums, is a naturallyoccurring complex polysaccharide with small amount of protein (2\%-3\%), which displays both emulsifying and emulsion stabilising properties (McClements, 2005; Ma et al., 2015). Therefore, the aim of this study was to determine the chemical composition and examine the emulsification properties of DOM in an oil-in-water emulsion with GA, in order to identify the main chemical components that contribute to the emulsifying property.

\section{Materials and methods}

\subsection{Materials}

Fresh Dioscorea opposita Thunb. was purchased in November 2015 from Bao He Tang (Jiaozuo) Pharmaceutical Co. Ltd., Jiaozuo city, Henan province, a farm located in 
Central China and known for Dioscorea opposita cultivation since approximately 2000 years. All reagents and standard samples including GA (Acacia senegal, G-9752) were purchased from Sigma-Aldrich Co. Ltd, USA, and Tianjin Kemiou Chemical Reagent Co. Ltd, China. All chemicals used were of analytical grade.

\subsection{Extraction of Dioscorea opposita mucilage (DOM)}

DOM was extracted as previously described by Andrade et al. (2015) with minor modifications. Briefly, approximately $4.0 \mathrm{~kg}$ fresh Dioscorea opposita was washed, peeled, and washed again in deionised water $(\mathrm{pH} 7.0$, conductance: $18 \mathrm{~m} \Omega$ ). Approximately 300 g portions of Dioscorea opposita were sliced and ground in an industrial blender for $5 \mathrm{~min}$. All portions were subsequently pooled and homogenised. After centrifugation at 4,000 rpm for $5 \mathrm{~min}$. DOM was collected in the supernatant and freeze-dried for 3 days to a constant weight to determine DOM yield. DOM was stored in vacuum desiccators over $\mathrm{P}_{2} \mathrm{O}_{5}$ until use.

\subsection{Analytical methods}

\subsubsection{Determination of glucose and protein content}

Glucose content and protein content were determined using phenol-sulphuric acid method and Coomassie brilliant blue method, respectively (Dubois et al., 1956; Bradford, 1976).

\subsubsection{Determination of monosaccharides}

As previously described by Andrade et al., (2015), gas chromatography-mass spectrometry (GC-MS, ThermoFisher Trace 1310 ISQ) was used for the quantitative determination of monosaccharides with HP-5MS $(30 \mathrm{~m} \times 0.25 \mathrm{~mm} \times 0.25 \mu \mathrm{m})$. A total 
109 of 8 standards (Ludger Co. Ltd) including fucose, arabinose, rhamnose, galactose,

110 glucose, mannose, xylose, and fructose were used to determine the monosaccharides in

111 DOM.

$112 \quad$ 2.3.3. Determination of amino acids

113 As previously described by Waqas et al. (2015), an amino acid analyser (L-8900

114 Amino acid analyser, Japan) and Shim-pack amino-Na column $(4.5 \times 60 \mathrm{~mm}$, Shimadzu $)$

115 were used to identify the amino acids in DOM.

116

\subsubsection{Determination of molecular weight (MW)}

117 The weight-average MW (Mw) and MW polydispersity (Mw/Mn) of DOM samples

118 were measured using high-performance size-exclusion chromatography attached to

119 multiangle laser light scattering and refractive index detector (HPSEC-MALLS-RID,

120 Wyatt Technology Co., USA) with an OHpak SB-802.5 HQ column $(8.0 \mathrm{~mm} \times 300 \mathrm{~mm}$,

121 Shodex Co., Japan). The mobile phase $\left(0.1 \mathrm{M} \mathrm{NaNO}_{3}\right)$ was pumped (Waters, 515 HPLC

122 Pump, USA) at a flow rate of $0.5 \mathrm{~mL} / \mathrm{min}, 50.0 \mu \mathrm{L}$ of sample solutions $(1.8 \mathrm{mg} / \mathrm{mL})$

123 was injected, and the chromatogram was analysed by using ARTRAV software (Wyatt

124 Technology Co., USA).

\subsection{5. $\mathrm{pH}$ determination}

DOM $(1 \% \mathrm{w} / \mathrm{v})$ was prepared and the $\mathrm{pH}$ meter (ZD-2A, Dapu Instrument,

127 Shanghai, China) was calibrated using standard solutions of known pH (4.00, 6.86 and

128 9.18). The $\mathrm{pH}$ value of the sample solutions was read directly from the instrument and

129 the mean value of two consecutive measurements was recorded. 

range of 400 to $4000 \mathrm{~cm}^{-1}$. The transmission of the samples within $7 \mathrm{~mm}$ diameter $\mathrm{KBr}$

133 pellets was measured.

\subsubsection{Scanning electron microscopy (SEM) and transmission electron}

135

136 $\mathrm{pH}$ 5.0, $\mathrm{pH} 7.0$, and $\mathrm{pH} 9.0$ ) overnight at $4{ }^{\circ} \mathrm{C}$ to equilibrate to the required $\mathrm{pH}$. Part of

151 the samples was freeze-dried and stored in vacuum desiccators over $\mathrm{P}_{2} \mathrm{O}_{5}$ for further 
152 study. The remaining samples were then dialysed against several changes of deionised

153 water for $24 \mathrm{hrs}$ at $4{ }^{\circ} \mathrm{C}$. No change in sample volume was observed. Materials were

154 freeze-dried and stored in vacuum desiccators over $\mathrm{P}_{2} \mathrm{O}_{5}$ for further study.

155

156

157

158

159

160

161

162

163

164 (a) Characterisation and monosaccharides of Dioscorea opposita mucilage

\begin{tabular}{lc}
\hline Characteristics & Average \pm SD \\
\hline Yield $(\%)$ & $8.18 \pm 0.08$ \\
Moisture $(\%)$ & $64.59 \pm 0.07$ \\
Glucose Content $(\%)$ & $16.00 \pm 0.06$ \\
Protein Content $(\%)$ & $2.78 \pm 0.48$ \\
Ash $(\%)$ & $16.00 \pm 0.12$ \\
pH & $6.96 \pm 0.02$
\end{tabular}

\begin{tabular}{lc}
\hline Monosaccharides (\%) & \\
Rhamnose & 0.25 \\
Arabinose & 0.54 \\
Xylose & 5.38 \\
Mannose & 33.40 \\
Glucose & 49.50 \\
Galactose & 10.90 \\
Uronic acid & ND \\
\hline
\end{tabular}


165 Note: ND = None detected; SD = standard deviation; fucose, galacturonic acid, and

166 glucuronic acid were tested and found below analytical detection limit.

167

168 (b) Amino acid composition, mean retention time (RTm) and peak area of Dioscorea

169 opposita mucilage

\begin{tabular}{lccc}
\hline \multicolumn{1}{c}{ Amino Acid } & Content $(\boldsymbol{\%})$ & RTm $(\mathbf{m i n})$ & Peak Area $\left(\times 10^{7}\right)$ \\
\hline Aspartic acid (ASP) & 4.16 & 5.18 & 5.73 \\
Threonine (THR) & 1.57 & 5.70 & 2.65 \\
Serine (SER) & 3.08 & 6.23 & 7.03 \\
Glutamic acid (GLU) & 4.55 & 7.01 & 7.10 \\
Glycine (GLY) & 1.38 & 10.11 & 3.61 \\
Alanine (ALA) & 1.73 & 10.91 & 4.45 \\
Cysteine (CYS) & 0.19 & 12.03 & 0.18 \\
Valine (VAL) & 1.69 & 12.63 & 3.23 \\
Methionine (MET) & 0.56 & 13.97 & 0.83 \\
Isoleucine (ILE) & 1.37 & 16.25 & 2.05 \\
Leucine (LEU) & 2.53 & 17.40 & 3.91 \\
Tyrosine (TYR) & 0.90 & 18.56 & 1.05 \\
Phenylalanine (PHE) & 1.96 & 19.47 & 2.47 \\
Lysine (LYS) & 1.71 & 21.57 & 2.70 \\
Tryptophan (TRP) & 0.56 & 22.68 & 0.83 \\
Histidine (HIS) & 0.81 & 23.75 & 1.10 \\
Arginine (ARG) & 4.35 & 28.44 & 4.29 \\
Proline (PRO) & 0.82 & 30.73 & 0.25 \\
\hline
\end{tabular}

170

171 (c) The molecular weight and distribution of Dioscorea opposita mucilage

\begin{tabular}{cc|cccc}
\hline \multicolumn{6}{c}{ MW factors of Dioscorea opposita mucilage } \\
\hline Polydispersity & & \multicolumn{4}{c}{ Molar mass moments (g/mol) } \\
\cline { 3 - 6 } Mw/Mn & Mz/Mn & Mn & Mp & Mw & Mz \\
6.715 & 238.841 & 21,390 & 12,610 & 143,700 & 511,000 \\
\multicolumn{7}{c}{} & & & & \\
\hline MW distributions (kDa) & & & & \\
$\mathbf{1 0 - 1 5}$ & $\mathbf{1 5 - 2 0}$ & $\mathbf{2 0 - 4 0}$ & $\mathbf{4 0 - 1 0 0}$ & $\mathbf{1 0 0 - 2 0 0}$ & $\mathbf{2 0 0 - 5 0 0}$ \\
$35.48 \%$ & $17.06 \%$ & $16.92 \%$ & $10.37 \%$ & $5.99 \%$ & $8.12 \%$ \\
\hline
\end{tabular}

172 Note: $\mathrm{Mn}=$ number-average $\mathrm{MW} ; \mathrm{Mp}=$ peak-average $\mathrm{MW} ; \mathrm{Mw}=$ weight-average 
$\mathrm{MW} ; \mathrm{Mz}=\mathrm{z}$-average $\mathrm{MW}$.

Table 1(a) shows the characterisation including yield, moisture, glucose content, protein content, ash, $\mathrm{pH}$ value, and monosaccharide composition of DOM. The yield of DOM was $8.18 \%$, including $64.59 \%$ moisture, $16.00 \%$ glucose, $2.78 \%$ protein, and $16.00 \%$ ash. Previous studies reported an yield of $9.63 \%$ and $4.20 \%$ for taro and bird's nest fern (Asplenium australasicum) mucilage, respectively (Andrade et al., 2015; Zeng \& Lai, 2016). Therefore, DOM yield in this study was of a reasonable value. The monosaccharides found in DOM were as follows in descending order: glucose, mannose, galactose, xylose, arabinose, and rhamnose $(49.50 \%>33.40 \%>10.90 \%>$ $5.38 \%>0.54 \%>0.25 \%$, respectively), while uronic acid was not detected. Three monosaccharides, glucose, mannose and galactose constituted approximately $93.8 \%$ of polysaccharide content, which could be in the form of a high concentration of glucomannan and galactomannan. On the other hand, GA, a commercial emulsifier containing $>97 \%$ polysaccharide and $2.5 \%$ protein, was used as a competitive control sample. GA is a member of the arabinogalactan-protein group and is a complex, branched heteropolyelectrolyte, with a backbone of 1,3-linked $\beta$-galactopyranose units and side-chains of 1,6-linked galactopyranose units terminating in a glucuronic acid or a 4-O-methylglucuronic acid residue (Dickinson, 2003).

Table 1(b) shows the amino acid content, mean retention time (RTm) and peak area of each amino acid found in DOM. A total of 18 types of amino acids were detected, including acidic polar amino acids with negative charge [such as glutamic acid $(4.55 \%)$ 
195 and aspartic acid (4.16\%)], basic polar amino acids with positive charge [such as

196 arginine (4.35\%) and lysine (1.71\%)], and neutral charge amino acid [such as serine

$197(3.08 \%)$, leucine $(2.53 \%)$, phenylalanine $(1.96 \%)$, alanine $(1.73 \%)$, valine $(1.69 \%)$,

198 threonine (1.57\%), glycine (1.38\%), and isoleucine (1.37\%)] (Damodaran et al., 1996).

199 Glutamate is commonly found in food and is known for its beneficial functions, such

200 as improving food flavour, enhancing food intake, and excitatory neurotransmitter

201 activity (Jinap \& Hajeb, 2010; Bellisle, 1999). In the 1970s, aspartic acid racemisation

202 was used to measure human dentine and monitor lens cataract formation during aging

203 (Helfman \& Bada, 1976; Masters et al., 1977). Similarly, Dioscorea opposita anorexic

204 and antioxidant effects, possibly contributed by glutamate and aspartic acid. Previous

205 studies have also suggested that arginine may contribute to seminal emission functions

206 (Food Chemistry, submitted).

207 Detailed molecular weight polydispersity and distribution are shown in Table 1(c).

208 Since DOM is a macromolecular compound, MW was determined in terms of $\mathrm{Mw}$

$209(143,700 \mathrm{Da})$, which was relatively more reliable than number-average molecular

210 weight $(\mathrm{Mn})$. The PDI (Mw/Mn) was 6.715, indicating a broad range of molecular

211 weight distribution $(10-500 \mathrm{kDa})$. The results show that DOM contains $52.54 \%$

212 macromolecules of size $<20 \mathrm{kDa}, 27.29 \%$ macromolecules of size between 20 and 100

$213 \mathrm{kDa}$, and $14.11 \%$ macromolecules of size $>100 \mathrm{kDa}$. A previous study showed that

214 crude polysaccharides in Dioscorea opposita comprised of approximately $55.51 \%$

215 macromolecules of size 0-20 kDa (Food Chemistry, Submitted). These results suggest 
216 that although MW of DOM much higher than that of Dioscorea opposita crude

217 polysaccharides, DOM contains a smaller proportion of smaller macromolecules.

218 3.2. Characteristics of Dioscorea opposita mucilage
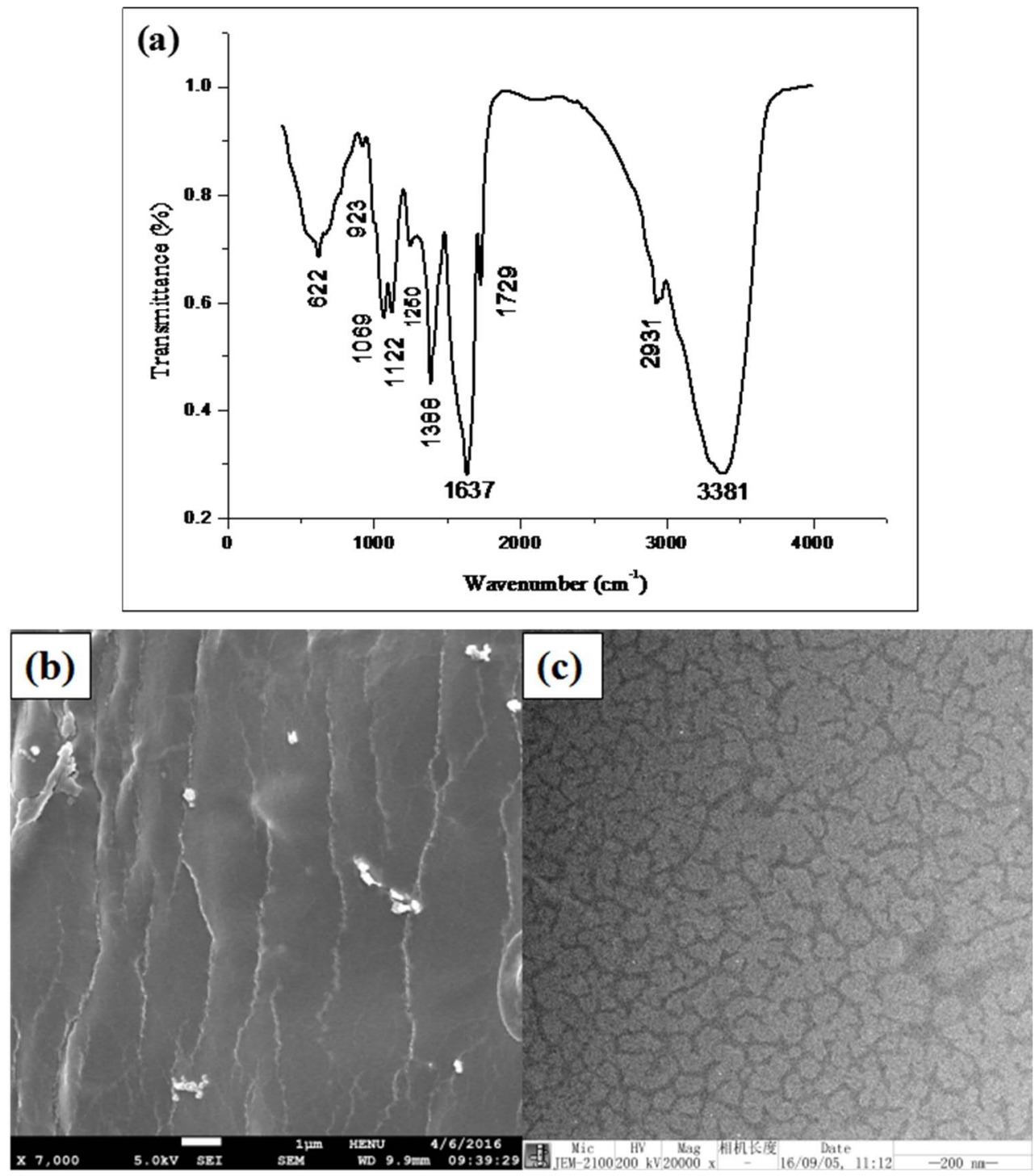

Fig. 1. Characterisation of Dioscorea opposita mucilage (DOM)

222 (a) Fourier transform infrared spectra of DOM; (b) Scanning electron microscopic 223 image of DOM at magnifications of $\times 7000$; (c) transmission electron microscopic 224 image of DOM at magnifications of $\times 20,000$ 

as shown in Fig. 1(c).

\subsubsection{FTIR} Chemistry, submitted).

\subsubsection{SEM \& TEM}

Fig. 1(a) shows the FTIR for DOM. The wide band at $3381 \mathrm{~cm}^{-1}$ indicates hydroxyl groups, and that at $2931 \mathrm{~cm}^{-1}$ indicates $\mathrm{CH}$ bond. The peak at $1729 \mathrm{~cm}^{-1}$ corresponds to carbonyl $(\mathrm{C}=\mathrm{O})$ in carboxylic acids, aldehydes, and ketones (Andrade et al., 2015). The wave number at $1637 \mathrm{~cm}^{-1}$ indicates the functional group of amide I band, mainly due to the $\mathrm{C}=\mathrm{O}$ stretching of peptide groups. The peaks at $1388 \mathrm{~cm}^{-1}$ and $1250 \mathrm{~cm}^{-1}$ indicate methyl group $\left(\mathrm{CH}_{3}\right)$ and $\mathrm{C}-\mathrm{O}$ stretching of carboxylic acids, respectively. Compared with FTIR of polysaccharides from Dioscorea opposita, no peak was observed for CO-H of carboxylic acid (noted in the range of 1395-1440 $\mathrm{cm}^{-1}$ ) for DOM (Food

Surface morphology images for DOM in the powder form, analysed by SEM and in solution, analysed by TEM are shown in Fig. 1(b) and (c), respectively. Previous studies show that surface topography, structure, and properties of polysaccharides may be influenced by the conditions of extraction, purification, and preparation (Nep \& Conway, 2010). DOM powder showed squamous structure, while DOM solution resembled a cracked film, similar to parched earth. DOM solution is viscous, thick, and easily forms a film. However, the concentration of mucilage in this study was low, which caused a relative decrease in cohesiveness, resulting in the cracked morphology, 
246 Table 2. Droplet diameter $(\mu \mathrm{m})$ and zeta-potential $(\mathrm{mV})$ of solution of gum arabic $(\mathrm{GA})$ and Dioscorea opposita mucilage (DOM) at different 247 concentrations

248 (a) Droplet diameter ( $\mu \mathrm{m})$ and polydispersity index (PDI) of GA and DOM solutions at different concentrations

Droplet diameter (z-average in $\mu \mathrm{m} \pm$ standard deviation with mean PDI in parentheses)

\begin{tabular}{|c|c|c|c|c|c|}
\hline & \multicolumn{5}{|c|}{ Concentrations (\% w/v) } \\
\hline & $0.2 \%$ & $0.4 \%$ & $0.6 \%$ & $0.8 \%$ & $1.0 \%$ \\
\hline GA & $0.16 \pm 0.02^{\mathrm{a}}(0.43)$ & $0.28 \pm 0.04^{\mathrm{ab}}(0.53)$ & $0.20 \pm 0.01^{\text {abc }}(0.54)$ & $0.28 \pm 0.03^{\text {acd }}(0.57)$ & $0.29 \pm 0.01^{\text {ace }}(0.38)$ \\
\hline DOM-N & $0.86 \pm 0.06^{\mathrm{af}}(0.56)$ & $0.93 \pm 0.08^{\mathrm{bg}}(0.57)$ & $1.09 \pm 0.09^{\mathrm{cfgh}}(0.54)$ & $1.25 \pm 0.06^{\mathrm{dfghi}}(0.39)$ & $1.45 \pm 0.04^{\text {efghij }}(0.46)$ \\
\hline DOM-pH 7 & $1.56 \pm 0.09^{\mathrm{afk}}(0.45)$ & $2.48 \pm 0.10^{\text {bgkl }}(0.47)$ & $2.85 \pm 0.07^{\text {chklm }}(0.51)$ & $3.23 \pm 0.06^{\mathrm{diklmn}}(0.39)$ & $5.56 \pm 0.11^{\text {ejklmno }}(0.46)$ \\
\hline DOM-pH 5 & $1.34 \pm 0.02^{\text {afkp }}(0.39)$ & $1.43 \pm 0.09^{\mathrm{bglq}}(0.62)$ & $1.44 \pm 0.02^{\mathrm{chmr}}(0.51)$ & $1.56 \pm 0.04^{\text {dinps }}(0.53)$ & $1.59 \pm 0.12^{\mathrm{eopt}}(0.36)$ \\
\hline DOM-pH 9 & $0.58 \pm 0.02^{\text {afkpu }}(0.57)$ & $0.68 \pm 0.01^{\text {bglquv }}(0.59)$ & $0.85 \pm 0.03^{\text {chmruvw }}(0.56)$ & $1.02 \pm 0.03^{\text {dinsuvwx }}(0.54)$ & $1.24 \pm 0.04^{\text {ejotuvwxy }}(0.53)$ \\
\hline DOM-pH 5-7 & $2.46 \pm 0.10^{\text {afkpu }}(0.49)$ & $3.12 \pm 0.08^{\mathrm{bglqv}}(0.36)$ & $3.18 \pm 0.07^{\mathrm{chmrw}}(0.25)$ & $4.24 \pm 0.08^{\mathrm{dinsx}}(0.30)$ & $4.85 \pm 0.37^{\text {ejoty }}(0.32)$ \\
\hline DOM-pH 9-7 & $1.06 \pm 0.09^{\text {afkpu }}(0.22)$ & $1.44 \pm 0.01^{\mathrm{bglv}}(0.46)$ & $1.53 \pm 0.05^{\mathrm{chmw}}(0.50)$ & $2.30 \pm 0.09^{\text {dinsx }}(0.34)$ & $2.79 \pm 0.08^{\text {ejoty }}(0.44)$ \\
\hline
\end{tabular}

249 Note: DOM-N = native DOM; Data are reported as mean of 6 replicates; Results are presented as mean \pm standard deviation; Paired values with

250 superscript letters a through y indicate significant difference $(\mathrm{P}<0.05)$. 


\begin{tabular}{lccccc}
\hline & \multicolumn{5}{c}{ Concentrations (\%w/v) } \\
\cline { 2 - 6 } & $\mathbf{0 . 2 \%}$ & $\mathbf{0 . 4 \%}$ & $\mathbf{0 . 6 \%}$ & $\mathbf{0 . 8 \%}$ & $\mathbf{1 . 0 \%}$ \\
\hline GA & $-27.70 \pm 3.27$ & $-28.70 \pm 0.66$ & $-24.47 \pm 2.56$ & $-21.90 \pm 0.53$ & $-22.80 \pm 0.53$ \\
DOM-N & $-45.90 \pm 1.68$ & $-44.68 \pm 0.87$ & $-45.57 \pm 1.07$ & $-46.67 \pm 1.61$ & $-51.48 \pm 0.81$ \\
DOM-pH 7 & $-47.50 \pm 1.51$ & $-47.33 \pm 1.36$ & $-49.60 \pm 1.51$ & $-53.50 \pm 1.31$ & $-57.00 \pm 1.65$ \\
DOM-pH 5 & $-47.37 \pm 3.29$ & $-40.47 \pm 0.59$ & $-40.60 \pm 0.26$ & $-38.73 \pm 1.29$ & $-37.97 \pm 1.67$ \\
DOM-pH 9 & $-38.83 \pm 1.27$ & $-39.43 \pm 1.80$ & $-38.77 \pm 0.32$ & $-40.80 \pm 0.98$ & $-44.10 \pm 0.30$ \\
DOM-pH 5-7 & $-55.80 \pm 2.60$ & $-56.97 \pm 2.23$ & $-56.23 \pm 0.86$ & $-55.57 \pm 1.00$ & $-54.87 \pm 2.50$ \\
DOM-pH 9-7 & $-45.87 \pm 3.25$ & $-54.47 \pm 2.23$ & $-64.00 \pm 3.22$ & $-70.80 \pm 2.78$ & $-60.80 \pm 5.97$ \\
\hline
\end{tabular}

252 Note: DOM-N = native DOM; Data are reported as mean of 6 replicates; Results are presented as mean \pm standard deviation. 
(a) Droplet diameter $(\mu \mathrm{m})$ and polydispersity index (PDI) of emulsions made from DOM and MCT at different concentrations

Droplet diameters (z-average in $\mu \mathrm{m} \pm$ standard deviation with mean PDI in parentheses)

\begin{tabular}{llllll}
\hline & \multicolumn{5}{c}{ Concentrations (\% w/v) } \\
\cline { 2 - 6 } & \multicolumn{1}{c}{$\mathbf{0 . 2 \%}$} & \multicolumn{1}{c}{$\mathbf{0 . 4 \%}$} & \multicolumn{1}{c}{$\mathbf{0 . 6 \%}$} & $\mathbf{0 . 8 \%}$ \\
\hline MCT & $2.89 \pm 0.07^{\text {a }}(0.35)$ & $1.94 \pm 0.03^{\text {ab }}(0.45)$ & $2.19 \pm 0.01^{\text {abc }}(0.54)$ & $2.44 \pm 0.04^{\text {abcd }}(0.89)$ & $2.68 \pm 0.01^{\text {abcde }}(0.61)$ \\
GA + MCT & $1.38 \pm 0.05^{\text {af }}(0.30)$ & $1.21 \pm 0.07^{\text {bfg }}(0.16)$ & $1.28 \pm 0.02^{\text {cfh }}(0.32)$ & $1.78 \pm 0.09^{\text {dfghi }}(0.16)$ & $1.68 \pm 0.06^{\text {efghj }}(0.06)$ \\
DOM -N + MCT & $1.04 \pm 0.07^{\text {afk }}(0.39)$ & $1.15 \pm 0.02^{\text {bl }}(0.17)$ & $1.74 \pm 0.03^{\text {chklm }}(0.15)$ & $1.74 \pm 0.01^{\text {dkln }}(0.19)$ & $2.52 \pm 0.32^{\text {jklmno }}(0.19)$ \\
DOM-pH 7 + MCT & $1.16 \pm 0.06^{\text {afp }}(0.54)$ & $1.38 \pm 0.05^{\text {blpq }}(0.34)$ & $1.95 \pm 0.05^{\text {chmpqr }}(0.20)$ & $2.15 \pm 0.12^{\text {dinpqs }}(0.43)$ & $2.38 \pm 0.09^{\text {ejpqrt }}(0.32)$ \\
DOM-pH 5 + MCT & $1.16 \pm 0.09^{\text {af }}(0.47)$ & $1.04 \pm 0.10^{\text {bgq }}(0.34)$ & $1.05 \pm 0.04^{\text {chmr }}(0.17)$ & $0.94 \pm 0.05^{\text {dins }}(0.20)$ & $1.07 \pm 0.03^{\text {ejot }}(0.30)$ \\
DOM-pH 9 + MCT & $0.39 \pm 0.01^{\text {afkp }}(0.23)$ & $0.41 \pm 0.01^{\text {bglq }}(0.20)$ & $0.43 \pm 0.02^{\text {chmr }}(0.16)$ & $0.47 \pm 0.02^{\text {dins }}(0.14)$ & $0.54 \pm 0.04^{\text {ejot }}(0.25)$ \\
DOM-pH 5-7 + MCT & $1.62 \pm 0.08^{\text {afkp }}(0.44)$ & $2.21 \pm 0.06 b^{\text {glq }}(0.16)$ & $2.28 \pm 0.08^{\text {hmr }}(0.22)$ & $3.56 \pm 0.06^{\text {dins }}(0.35)$ & $3.80 \pm 0.02^{\text {ejot }}(0.28)$ \\
DOM-pH 9-7 + MCT & $0.94 \pm 0.06^{\text {afp }}(0.28)$ & $1.80 \pm 0.09^{\text {glq }}(0.64)$ & $2.38 \pm 0.06^{\text {chmr }}(0.55)$ & $2.96 \pm 0.06^{\text {dins }}(0.36)$ & $3.72 \pm 0.09^{\text {ejot }}(0.49)$ \\
\hline
\end{tabular}

256 Note: DOM-N = native DOM; Data are reported as mean of 6 replicates; Results are presented as mean \pm standard deviation; Paired values with 
(b) Zeta-potential (mV) of emulsions made from DOM and MCT at different concentrations

\begin{tabular}{lccccc}
\hline & \multicolumn{5}{c}{ Concentrations (\%w/v) } \\
\cline { 2 - 6 } & $\mathbf{0 . 2 \%}$ & $\mathbf{0 . 4 \%}$ & $\mathbf{0 . 6 \%}$ & $\mathbf{0 . 8 \%}$ & $\mathbf{1 . 0 \%}$ \\
\hline MCT & $-32.38 \pm 0.45$ & $-32.83 \pm 2.50$ & $-35.20 \pm 0.62$ & $-35.30 \pm 0.80$ & $-30.80 \pm 1.14$ \\
GA + MCT & $-38.17 \pm 2.65$ & $-34.80 \pm 0.87$ & $-29.70 \pm 0.10$ & $-29.01 \pm 0.97$ & $-27.75 \pm 1.42$ \\
DOM-N + MCT & $-49.88 \pm 0.70$ & $-44.38 \pm 1.33$ & $-44.77 \pm 0.06$ & $-41.97 \pm 1.16$ & $-45.17 \pm 0.91$ \\
DOM-pH 7 + MCT & $-47.83 \pm 1.82$ & $-42.60 \pm 1.65$ & $-43.40 \pm 1.35$ & $-46.70 \pm 0.95$ & $-46.47 \pm 1.04$ \\
DOM-pH 5 + MCT & $-46.00 \pm 0.72$ & $-41.80 \pm 1.47$ & $-41.97 \pm 0.67$ & $-40.60 \pm 0.87$ & $-40.83 \pm 0.25$ \\
DOM-pH 9 + MCT & $-57.10 \pm 1.59$ & $-51.43 \pm 2.07$ & $-46.57 \pm 1.11$ & $-43.30 \pm 0.35$ & $-40.83 \pm 1.46$ \\
DOM-pH 5-7 + MCT & $-55.30 \pm 3.88$ & $-52.87 \pm 1.50$ & $-56.90 \pm 1.15$ & $-56.03 \pm 0.59$ & $-57.07 \pm 3.39$ \\
DOM-pH 9-7 + MCT & $-58.73 \pm 1.01$ & $-58.90 \pm 1.49$ & $-58.80 \pm 1.30$ & $-60.40 \pm 2.13$ & $-62.77 \pm 1.64$ \\
\hline
\end{tabular}

259 Note: DOM-N = native DOM; Data are reported as mean of 6 replicates; Results are presented as mean \pm standard deviation. 


\subsection{Emulsification properties of DOM}

\subsubsection{Particle diameters and stability of DOM solution}

Table 2(a) shows the droplet size of DOM solutions at different concentrations. DOM solution samples tested included native DOM (DOM-N), pH-treated DOM (DOM-pH 7, DOM-pH 5, and DOM-pH 9), and DOM neutralised after pH treatment (DOM-pH 5-7 and DOM-pH 9-7). The results indicate a trend where particle size diameters increased with an increase in concentration, which may be caused by flocculation. Particle size values for the commercial emulsifier, GA at different concentrations were in the range of $0.16-0.29 \mu \mathrm{m}$, whereas that for native DOM ranged from $0.86 \mu \mathrm{m}$ to $1.45 \mu \mathrm{m}$. Compared with that of GA $(<0.30 \mu \mathrm{m})$, the droplet size of DOM samples was much larger $(>0.8 \mu \mathrm{m})$.

The droplet diameters of DOM-N, DOM-pH 7, DOM-pH 5, and DOM-pH 9 were in the range of $0.86-1.45,1.56-5.56,1.34-1.59$, and $0.58-1.24 \mu \mathrm{m}$, respectively. Although the $\mathrm{pH}$ value of DOM-N was 6.96 (Table 1(a)), close to $\mathrm{pH} 7.0$, the droplet size of DOM-pH 7 was significantly larger than that of DOM-N. DOM-pH 7 was dialysed overnight against buffer solutions and the membrane used was 8-14 kDa. As shown in Table 1(c), since approximately $35.48 \%$ of the macromolecules within DOM measured between 10 and $15 \mathrm{kDa}$, smaller particles may have been removed during dialysis, resulting in larger droplets formed by DOM-pH 7.

The droplet diameter of DOM-pH 5 was larger than that of DOM-N, but smaller than that of DOM-pH 7. Moreover, the droplet size of DOM-pH 9 was significantly smaller than that of both DOM-N and DOM-pH 7. Both, acidic and alkaline conditions 
resulted in smaller particle size, more so in the case of alkaline conditions. The results

283 from FTIR for amino acids showed a higher proportion of acidic groups in DOM.

284 Therefore, acidic conditions did not affect droplet size of DOM to a large extent;

285 however, alkaline conditions may have caused stereochemical reactions which altered

286 the functional groups and resulting structure of DOM.

287 After $\mathrm{pH}$ treatment, DOM-pH 5 and DOM-pH 9 were dialysed against several 288 changes of deionised water for $24 \mathrm{hrs}$ at $4{ }^{\circ} \mathrm{C}$ until the $\mathrm{pH}$ value returned to 7 . The 289 droplet diameter of DOM-pH 5-7 was significantly larger than that of DOM-N and 290 DOM-pH 7. Meanwhile, DOM-pH 9-7 droplet sizes reverted to that of DOM-N and 291 lower. The acidic condition may have provided additional $\mathrm{H}^{+}$ions, and following 292 dialysis with deionised water, smaller hydrolysed DOM particles (MW $<8 \mathrm{kDa}$ ) could 293 have been removed during dialysis, which may have resulted in the increase in DOM 294 particle diameter. The alkaline conditions, on the other hand, introduced additional $\mathrm{OH}^{-}$ 295 groups, which combined with dissociated $\mathrm{H}^{+}$ions, which in turn may have resulted in 296 a change in DOM structure, causing the polysaccharides chains to repel each other. 297 Either way, the macromolecules separated into relatively smaller structures to achieve 298 smaller particle size (Wu et al., 2015).

Table 2(b) shows the zeta-potential of DOM solution at different concentrations.

300 Zeta-potential is an indicator of the stabilities of emulsions. If the absolute value of 301 zeta-potential is > 30, the hydrocolloid is considered stable (Williams \& Phillips, 2009). 302 The zeta-potential values of GA were close to $| \pm 30|$, while those of DOM-N samples 303 were over $| \pm 40|$, suggesting relatively good stability of DOM. Compared with the 
zeta-potential value of DOM-N, DOM-pH 7 showed a higher value. The zeta-potential values of DOM-pH 7, DOM-pH 5, and DOM-pH 9 were in the range of -57 to -47.5 , 37.97 to -47.37 , and -44.10 to $-38.83 \mathrm{mV}$, respectively.

The results from this study show similarity to a report by Nakauma et al. (2008), who showed that a decrease in $\mathrm{pH}$ causes a decrease in zeta-potential. However, after treatment at $\mathrm{pH} 9$, the increase in $\mathrm{pH}$ caused a decrease in the zeta-potential in this study, which contradicts the findings by Nakauma et al. (2008). Since DOM was slightly acidic, more $\mathrm{H}^{+}$ions available in solution and zeta-potential of the original DOM sample was negative. Therefore, the zeta-potential decreased slightly under acidic conditions. The increase in $\mathrm{pH}$ provided more $\mathrm{OH}^{-}$ions, which combined with dissociated $\mathrm{H}^{+}$and caused the macromolecules to reconfigure their structure as the the negatively charged polysaccharide chains would repel each other. Therefore, the potential of $\mathrm{pH}$-treated DOM caused a change in the zeta-potential.

After several rounds of dialysis against deionised water, the $\mathrm{pH}$ value of $\mathrm{pH}$-treated DOM samples was adjusted back to neutral. The zeta-potential values of DOM-pH 5-7 and DOM-pH 9-7 were in the range of -54.87 to $-56.97 \mathrm{mV}$ and -45.87 to $-70.80 \mathrm{mV}$, respectively, which were higher than that of DOM-pH 7. The results show that DOM may undergo a change in structure and functional groups after $\mathrm{pH}$ treatment, which is consistent with the results reported by Nakauma et al. (2008). Thus, the zeta-potential value is not the only criterion to determine emulsion stability. According to $\mathrm{Wu}$ et al. (2015), emulsion stability is determined by several factors including amino acid 
composition, isoelectric point, and conformation of polysaccharides; an increase in polysaccharide concentration also causes an increase in stability of emulsions.

\subsubsection{Emulsification properties of DOM with MCT}

Table 3(a) shows the droplet size (z-average, $\mu \mathrm{m}$ ) and PDI of emulsions stabilised by GA, DOM native (DOM-N), pH treated DOM samples (DOM-pH 7, DOM-pH 5 and DOM-pH 9), and neutralised DOM after pH treatment (DOM-pH 5-7 and DOM$\mathrm{pH}$ 9-7) with MCT. The droplet size of most emulsions showed an increasing trend with an increase in concentration, with a few exceptions such as $0.8 \% \mathrm{w} / \mathrm{v} \mathrm{GA}+\mathrm{MCT}, 0.8 \%$ w/v DOM + MCT, 0.8\% w/v DOM-pH 5 + MCT, and DOM-pH 9-7 + MCT.

The droplet sizes of MCT alone in water was in the range of 1.94 to $2.89 \mu \mathrm{m}$. The emulsions made from GA + MCT, and DOM + MCT (ratios = 1: 1) showed a decrease in droplet size in the range of 1.21 to $1.78 \mu \mathrm{m}$, and 1.04 to $2.52 \mu \mathrm{m}$, respectively. The droplet size of pH-treated DOM including DOM-pH 7, DOM-pH 5, and DOM-pH 9 was in the range of 1.16 to $2.38,0.94$ to 1.16 , and 0.39 to $0.54 \mu \mathrm{m}$, respectively. After dialysis against deionised water, molecules $<8 \mathrm{kDa}$ in size passed through the membrane and therefore, the droplet sizes of DOM-pH 7 was larger than that of DOMN. On the other hand, DOM-pH 5 showed similar/slightly smaller droplet size than DOM-pH 7, while, DOM-pH 9 showed a much smaller droplet size compared with DOM-pH 7. The results are consistent those shown in Table 2, which also suggest that $\mathrm{OH}^{-}$ions in an alkaline aqueous solution may cause the polysaccharide chains to repel each other. Oil droplets coalesce because of the decrease in electrostatic repulsion (Wu et al., 2015). Protein in DOM contains hydrophobic groups and polysaccharides contain 
347 hydrophilic groups, which repel each other. Therefore, the same amount of MCT would 348 require a lower quantity of protein and polysaccharides, which may relate to 349 conformational change or depolymerisation of the carbohydrate portion, reducing the 350 steric effect (Nakauma et al., 2008).

351 At neutralised $\mathrm{pH}$, the droplet size of DOM-pH 5-7 and DOM-pH 9-7 was in the 352 range of 1.62 to 3.80 and 0.94 to $3.72 \mu \mathrm{m}$, respectively, which is larger than that of both 353 DOM-N and corresponding DOM-pH-treated. The results show that the $\mathrm{pH}$-treated 354 DOM samples were unable to recover the emulsifying ability of DOM-N. Compared 355 with MCT alone, DOM-N exhibited better emulsification properties, indicating that 356 DOM should be investigated further as a natural unconventional food additive. Table 3(b) lists the zeta-potential values of emulsions made from GA and DOM 358 samples with MCT. The zeta-potential value of each DOM sample (> $40 \mathrm{mV}$ ) was 359 higher than that of MCT alone as well as of emulsions made from GA and MCT 360 (approximately $30 \mathrm{mV}$ ). However, according to $\mathrm{Wu}$ et al. (2015), zeta-potential, 361 especially at different $\mathrm{pH}$ values, does not necessarily lead to a more stable emulsion 362 due to $\mathrm{H}^{+}$and $\mathrm{OH}^{-}$ions affecting the isoelectric point. Taken together, data in Table 3(a) 363 and (b) show that mucilage obtained from Dioscorea opposita exhibits superior 364 emulsification properties compared with GA. 

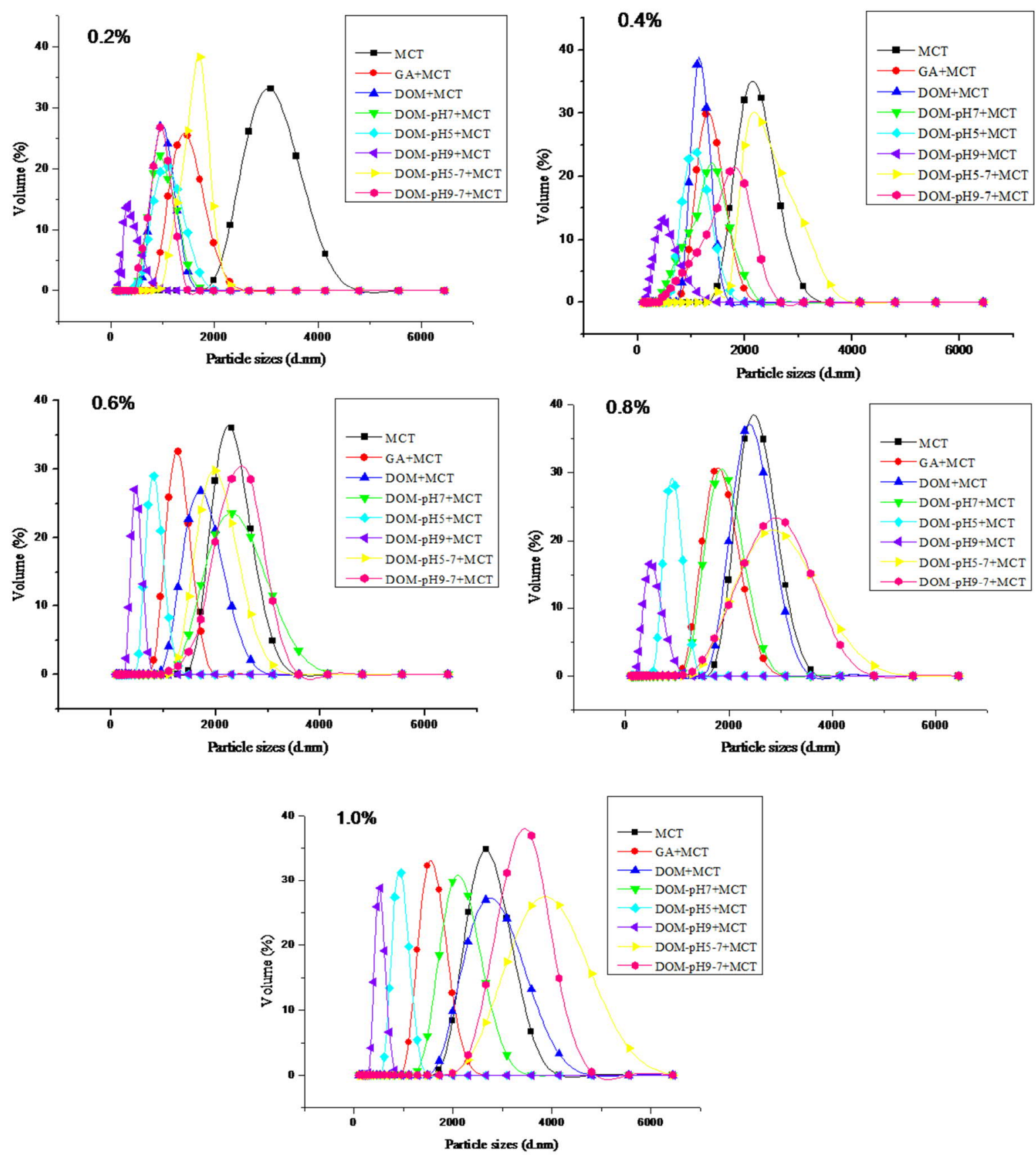

366 Fig. 2. Droplet size and distribution of freshly prepared emulsions. The ratio of GA +

367 MCT and DOM + MCT was $1: 1$ at different concentrations of $0.2 \%, 0.4 \%, 0.6 \%, 0.8 \%$,

368 and $1.0 \% \mathrm{w} / \mathrm{v}$. Data is presented as mean from 6 replicates. 
371 emulsions stabilised by GA and DOM at different concentrations. The peaks of

372 emulsions at $0.2 \% \mathrm{w} / \mathrm{v}$ concentration were tightly distributed at approximately 1,000

$373 \mathrm{~nm}$, whereas the peak for MCT $(0.2 \% \mathrm{w} / \mathrm{v})$ alone appears at 2,890 $\mathrm{nm}$. The peaks of

374 emulsions made from GA and MCT were quite stable, in the range of 1,210 to 1,780

$375 \mathrm{~nm}$, while those from DOM and MCT were in the range of 1,040 to $2,520 \mathrm{~nm}$ at

376 different concentrations $(0.2 \%$ to $1.0 \% \mathrm{w} / \mathrm{v})$. The smallest droplet diameters at each

377 concentration $(0.2 \%, 0.4 \%, 0.6 \%, 0.8 \%$, and $1.0 \%$ w/v) corresponded to DOM-pH 9

$378(390,410,430,470$, and $540 \mathrm{~nm}$, respectively), suggesting that the increase in $\mathrm{pH}$ not

379 only increased the zeta-potential value (Table 3(b)), but also lowered the droplet size.

380 The $\mathrm{pH}$ 5-treated DOM also showed smaller droplet size, with diameters of 1160, 1040,

3811050,940 , and $1070 \mathrm{~nm}$ for increasing concentrations of $0.2 \%$ through $1.0 \% \mathrm{w} / \mathrm{v}$,

382 respectively. The results indicate that DOM shows superior emulsification ability at

383 lower concentrations, with $\mathrm{pH}$ 9-treated DOM showing optimum emulsifying function

384 with small droplet size and high zeta-potential values.

\section{Conclusion}

This study was carried out to investigate the emulsification properties of DOM

388 compared with GA at different concentrations and $\mathrm{pH}$ treatments. Large droplet

389 diameter of DOM solution showed higher zeta-potential compared with that of GA.

390 Emulsions made from DOM and MCT presented greater stability, especially at lower

391 concentrations. The native $\mathrm{pH}$ values were 6.96 and 4.49 for DOM and GA solutions, 
392

393

394 isoelectric point of amino acids, which would cause the polysaccharide chains to repel

395 each other. Therefore, though the zeta-potential value increased rapidly with a change

396 in $\mathrm{pH}$, the stability of the emulsion may not be affected.

397 398 obtained from Dioscorea opposita could be considered as a natural emulsifier, 399 especially under alkaline conditions and is a sustainable resource obtained from 400 industrial processing waste.

401

402

403

404

405

406

407

408

409

410

411

413

In conclusion, considering the droplet size and zeta-potential value, mucilage

\section{Acknowledgments}

We are grateful for financial support from College Science and Technology Innovation Team Program of Henan Province (No. 14IRTSTHN030), Foundation of

Science and Technology Department of Henan Province (No. 152102210054), and Foundation for Young-backbone Teachers of Higher Education Institutions in Henan Province (No. 2014GGJS-023).

\section{References}

Andrade, L.A., Nunes, C.A. \& Pereira, J. (2015). Relationship between the chemical components of taro rhizome mucilage and its emulsifying property. Food Chemistry, 178, 331-338.

Bellisle, F. (1999). Glutamate and the UMAMI taste: sensory, metabolic, nutritional 

years. Neuroscience and Biobehavioral Reviews, 23(3), 423-438.

416 Bradford, M.M. (1976). A refined and sensitive method for the quantification of microgram quantities of protein utilizing the principle of protein-dye binding. Analytical Biochemistry, 72, 248-254.

Capitani, M.I., Nolasco, S.M. \& Tomás, M.C. (2016). Stability of oil-in-water (O/W) emulsions with chia (Salvia hispanica L.) mucilage. Food Hydrocolloids, 61, 537546.

Damodaran, S. (1996). Amino acids, peptides, and proteins. In O.R. Fennema (Ed.), Food Chemistry (pp. 321-429). USA: CRC Press.

Dickinson, E. \& Stainsby, G. (1988). Advances in Food Emulsions and Foams. London: Elsevier Applied Science.

Dubois, M., Gilles, K.A., Hamilton, J.K., Reders, P.A.,\& Smith, F. (1956). Colorimetric

Helfman, P.M., \& Bada, J.L. (1976). Aspartic acid racemisation in dentine as a measure of aging. Nature, 262(5566), 279-281.

431 Herlina (2015). Deproteinase effect of hydrocolloid flour made of "Gembili Tuber" (Dioscorea esculenta L.) on chemical and technical functional properties. Technology, 5(4),298-302.

435 Huang, Z., Liang, Z., Li, G.,\& Hong, H. (2011). Response surface methodology to 
extraction of Dioscorea polysaccharides and the effects on rat's bone quality. Carbohydrate Polymers, 83(1), 32-37.

Hsu, C.L., Chen, W., Weng, Y.M.,\& Tseng, C.Y. (2003). Chemical composition, physical properties and antioxidant activities of yam flours as affected by different drying methods. Food Chemistry, 83(1), 85-92.

Idris, O.H.M. \& Haddad, G.M. (2012). Gum arabic's (gum Acacia's) journey from tree to end user. In J.F. Kennedy, G.O. Phillips \& P.A. Williams (Eds.), Gum Arabic(pp. 3-17). Croydon: The Royal Society of Chemistry.

Jinap, S. \& Hajeb, P. (2010). Glutamate. Its applications in food and contribution to health. Appetite, 55(1),1-10.

Kiho, T., Hara, C. \& Ukai, S. (1985). A glucomannan from the tubers of Dioscorea

Lee, M.H., Lin, Y.S., Lin, Y.H., Hsu, F.L. \& Hou, W.C. (2003). The mucilage of yam (Dioscorea batatas Decne) tuber exhibited angiotensin converting enzyme

Li, H., Wu, Z., Liu, W., Li, Z., Hu, N. \& Huang, D. (2016). Recovery of yam mucilage from the yam starch processing wastewater by using a novel foam fractionation treatments on the emulsification properties of gum arabic. Food Chemistry, 184, 114-121. 
Masters, P.M., Bada, J.L., \& Zigler JR, J.S. (1977). Aspartic acid racemisation in the human lens during aging and in cataract formation. Nature, 268(5615), 71-73.

McClements, D.J. (2005). Food Emulsions, Principles, Practice, and Techniques. London: CRC Press.

Myoda, T., Matsuda, Y., Suzuki, T., Natagawa, T., Nagai, T. \& Nagashima, T. (2006). Identification of soluble proteins and interaction with mannan in mucilage of Dioscorea opposita Thunb. (Chinese yam tuber). Food Science and Technology Research, 12(4), 299-302.

Nakauma, M., Funami, T., Noda, S., Ishihara, S., Al-Assaf, S., Nishinari, K. \& Phillips, G.O. (2008). Comparison of sugar beet pectin, soybean soluble polysaccharide, and gum arabic as food emulsifier. 1. Effect of concentration, $\mathrm{pH}$, and salts on the emulsifying properties. Food Hydrocolloids, 22(7), 1254-1267.

Nep, E.I. \& Conway, B.R. (2010). Characterization of grewia gum, a potential pharmaceutical excipient. Journal of Excipients and Food Chemicals, 1(1), 30-40.

Ohtani, K. \& Murakami, K. (1991). Structure of mannan fractionated from watersoluble mucilage of nagaimo (Dioscorea batatasDence). Agricultural and Biological Chemistry, 55(9), 2413-2414.

Télessy, I.G., Balogh, J., Csempesz, F., Szente, V., Dredán, J. \& Zelkó, R. (2009), Comparison of the physicochemical properties of MCT-containing fat emulsions in total nutrient admixtures. Colloids and Surfaces B: Biointerfaces, 72(1), 75-79. Xue, Y., Miyakawa, T., Nakamura, A., Hatano, K., Sawano, Y. \& Tanokura, M. (2015). Yam tuber storage protein reduces plant oxidants using the coupled reactions as 

1118.

Waqas, M., Khan, A.L., Hamayun, M., Shahzad, R., Kim, Y.H. \& Choi, I.J. (2015). Endophytic infection alleviates biotic stress in sunflower through regulation of defence hormones, antioxidants and functional amino acids. European Journal of Plant Pathology, 141(4), 803-824.

Williams, P.A. \& Phillips, G.O. (2009). Handbook of Hydrocolloids, $2^{\text {nd }}$ Edition. Oxford: Woodhead Publishing Limited.

Wu, Y., Eskin, N.A.M., Cui, W. \& Pokharel, B. (2015). Emulsifying properties of water soluble yellow mustard mucilage: A comparative study with gum arabic and citrus pectin. Food Hydrocolloids, 47, 191-196.

Yang, D. \& Lin, J. (2008). Effects of different storage conditions on steroidal saponins in yam (Dioscorea pseudojaponica Yamamoto) tubers. Food Chemistry, 110(3), 670-667.

Zeng, W. \& Lai, L. (2016). Characterization of the mucilage extracted from the edible fronds of bird's nest fern (Asplenium australasicum) with enzymatic modifications. Food Hydrocolloids, 53, 84-92.

Zhang, Z., Wang, X., Liu, C. \& Li, J. (2016). The degradation, antioxidant and 498 antimutagenic activity of mucilage polysaccharide from Dioscorea opposita. Carbohydrate Polymers, 150, 227-231. 